\title{
Strange encounters: A series of posters investigating the hybrid embodiment of Indo-Canadian identity
}

\author{
Krishna Balakrishnan / York University / Toronto / Canada
}

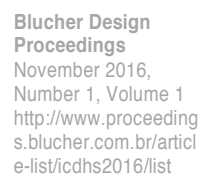

\begin{abstract}
Postmodernism has been important in acknowledging many forms of "otherness" that emerge from differences in subjectivity, gender, race, class, temporal, spatial geographic location and dislocation. This has become a topic of interest among graphic designers as they explore design's relationship with culture. This project, a series of creatures called The Avatars explore the use of graphic design to produce visual artifacts that discuss hybrid embodiment of IndoCanadian identity. Using hybridity, Homi Bhabha's concept of a "third space" identifies a metaphor for the space in which cultures meet. Where communication, negotiation, and translation bridge societies, a new space emerges.
\end{abstract}

\section{Keywords}

Graphic design, cultural hybridity, Culture, identity, third space

\section{Introduction}

Articulating and enunciating concepts of cultural hybridity in graphic design not only helps to comprehend the evolving cultural identities of multiculturalism and migrant experience, but also promotes alternative ways of representing in-between cultural spaces. The posters series, The Avatars, created by Krishna Balakrishnan are a digital montage of Hindu gods and goddesses, comic-book superheroes and Disney princesses. They are metaphoric representations analogous to the embodiment of Indian-Canadian (Indo-Canadian) identity. The designer attempts to discuss complex ideas of migrant identity, difficulties in translating vernaculars-images and symbols across cultures, and negotiate the representation of a meeting space between strangers. All of these questions highlight postmodernism's concern for difference, difficulties in communication, and complexities and nuances of interests, cultures, and place.

The Avatars (Fig. 1-4) are a series of hybrid creatures, mutations, or a combination of strangers, which depict negotiation of their prescribed representation. On one hand, The Avatars make use of comicbook vernacular and children's cartoon characters from Western popular culture while on the other hand, The Avatars depict Indian Hindu gods and goddesses. These juxtaposing vernaculars from distinct cultural contexts meet in their hybrid embodiment. In this embodiment, the boundaries that contain static identities are dissolved. Attempting to visually read The Avatars forces one to negotiate these juxtaposed identities. The Avatars' construction asks questions of their configuration: Why are they in this mutated form? What is their relationship to one another? Cultural identities are represented as negotiating against one another, and as a result the hybrids are recognized as either contesting or harmonious in their embodiment.

To understand The Avatars, one needs to forgo traditional representations of being an Indian and a Canadian. The Avatars' bodies are never complete; they are in the process of "becoming" their new embodiment, and "destructing" their former selves. Sacred images in Hinduism are temporal, incomplete, and inadequate as a full expression (Preston, 1985). The sacred images of Hindu gods are constructed according to systematic rules, and then are infused with sacrality and kept "alive" by highly controlled behaviours intended to retain the "spirit in matter" (Preston, 1985). Hinduism is an imaginative, "image-making" religious tradition in which the sacred is seen as present in the visible world-in multiple images and deities, in sacred places, in people, in every locus of Indian life (Eck, 1998). The behaviours Indians exhibit towards sacred images is brought to their immigrant land and changes accordingly upon interactions with new experiences.

The superheroes are representations of godlike presence in American "material" popular culture. 
Their images are produced in similar quantity as those of the Hindu gods-in product packaging, films, posters and whatever corporations can exploit in their trademark. Though the superheroes of The Avatars can be perceived as American, they have roots in every country, where, around the turn of the twentieth century, the comic industry expanded from publication newspaper and strips to circulation in collections and serials. Canadian culture, so close in proximity to the United States, is heavily influenced by American superheroes. Today, comic studies have been integrated into many university programs of world literature, and represent a form of storytelling art rooted in transcultural imaginations.
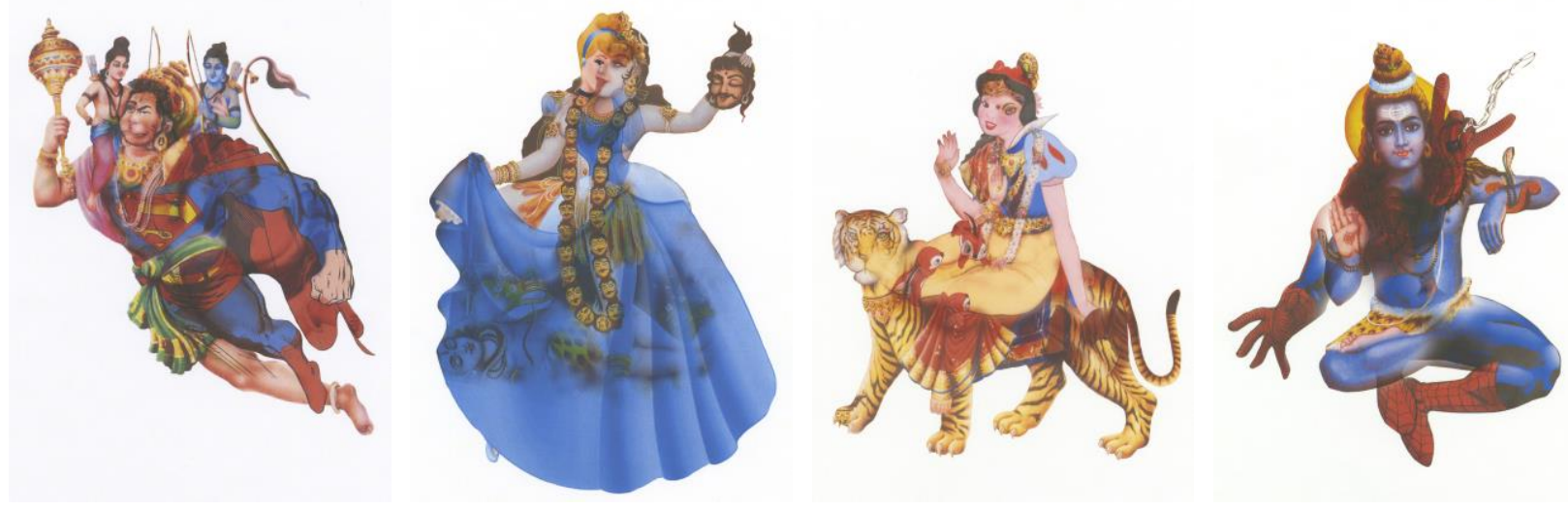

Fig. 1-4: The Avatars

The medium of collage is also used to represent hybridity. The Avatars' incorporate image reproduction of characters that are familiar and different. The gods and superheroes are products of mass printing. One does not need to travel far to encounter Indian gods. Their adoption by global culture has seen Krishna and Kali appear on CD covers, diaries, websites, clothing, and fashion accessories. The superheroes and princesses are part of the Hollywood popular material cultures and their images are mass reproduced. In this way, the Hindu gods can be seen as popular images that represent India or Indian-ness. The mass consumption and presence of superheroes gives them the power to be seen as gods of Hollywood material culture. Through juxtaposing one element to another, the images make us rethink the significance of all familiar images. The Avatars appear estranged, otherworldly, in-between the possible and the impossible or unlikely, and in a space between real and simulated. By its nature, the collage becomes an interpretation-an expression of opinion. Collages' interpretative qualities make them "uniquely suited to the job of bringing the world and its cultural efflorescence into close proximity, with no burden to mimic reality or impart truths" (Hoptman, 2007, p. 11). The Avatars, in expressing the duality of Indian and Indian-Canadian identity, become a form of strategy, a resistance to the world they inhabit. Difference and similarities of images asks us to imagine them in an alternative way.

While one recognizes the positive contribution of multiculturalism in producing cultural diversity, theorists and writers such as Stuart Hall, Homi Bhabha, Salman Rushdie, bell hooks, and Sara Ahmed emphasize the importance of cultural differences for notions of hybridity. Multiculturalism is an attempt to both respond to and control the dynamic process of articulating cultural difference, demanding a consensus based on a norm that cultivates cultural diversity (“The Third Space: Interview with Homi Bhabha," 1990 ). For Bhabha (1990), the liberal relativist perspective of cultural diversity is inadequate, and does not recognize the universality and normative stance from which it constructs cultural and political judgments. Ahmed (2000) describes multiculturalism as the proximity of strangers. The strangers are not simply those already recognized as out of place; rather, in a multicultural nation, strangers have a place. Ahmed (2000) argues further that multiculturalism can involve a double and contradictory process of incorporation and expulsion: it may seek to differentiate between strangers whose appearance of difference can be claimed by the nation, and those whose differences may be dangerous to the well-being of even heterogeneous nations. The proximity of strangers requires constant adjustment and transformation (Ahmed, 2000). With the notion of cultural difference, Bhabha (1990) positions himself within liminality-the in-between, productive space in the construction of culture as difference or otherness. However rational one is, it is very difficult, and even counter productive to try and fit together different forms of culture, and to pretend they can easily coexist.

The Avatars are not about seeing the Western-ness or Indian-ness, but rather seeing a unique in-between space of negotiation-a Third Space. Bhabha (2006) notes that this Third Space intervention makes the 
structure of meaning and reference an ambivalent process; it destroys mirrored representation, and reveals cultural knowledge as continuous, integrated, open, and expanding code. Such intervention challenges our sense of "the historical identity of culture as a homogenizing, unifying force, authenticated by the original Past, and kept alive in the national tradition of the People" (Bhabha, 2006, p. 156). The Avatars' enunciation displaces the narrative of Western's perception, which Bhabha (2006) describes as being written in homogeneous, linear time. The Avatar as a metaphor of Indo-Canadian identity asks one to re-examine their own perception of the migrant stranger.

Psychologist and cognitive scientist Lawrence Barsalou points out that we process concepts not as abstract, detached combinations of features, but rather as "agent-dependent instruction manuals" to run an embodied simulation (Kukkonen, 2013). These embodied simulations are tied to the context of particular situations, which include the objects and agents involved, actions and bodily states, motivations, emotions, cognitive operations and often settings. The embodied situations evoked by The Avatars places the images in the situation of the Indo-Canadian self, whereby the migrant experience is understood as a perception. Migrant individuals perceive notions of "difference" in the new environment, but are those "differences" analogous to the Canadian experience? Seeing and reading images in the migrant's perspective, one can experience a sense of double embodiment. Reading the images of The Avatars in terms of a situated conceptualization brings the formerly individual (gods and pop characters) together in analysis; embodiment and composition contribute to creating an embodied simulation of the migrant experience. IndoCanadian identity is continuously changing and The Avatars, as a metaphor of migrant experience, represent such change.

\section{References}

(1990). The Third Space: Interview with Homi Bhabha. In J. Rutherford (Ed.), Identity: Community, Culture, Difference. London: Lawrence \& Wishart.

Ahmed, S. (2000). Stranger Encounters: Embodied Others in Post-Coloniality. London: Routledge.

Bhabha, H. (2006). Cultural Diversity and Cultural Differences. In B. Ashcroft, G. Griffiths \& H. Tiffin (Eds.), The Post Colonial Studies Reader. New York: Routledge.

Eck, D. L. (1998). Darsan: Seeing the Divine in India. Delhi: Motilal Banarsidass.

Hoptman, L. (2007). Collage: The UnMonumental Picture. London: Merrel.

Kukkonen, K. (2013). Space, Time and Causality in Graphic Narratives: An Embodied Approach. In D. Stein \& J. Thon (Eds.), Narratologia: From Comic Strips to Graphic Novels: Contributions to the Theory and History of Graphic Narrative. Berlin: De Gruyter.

Preston, J. (1985). Creation of the Sacred Image: Apotheosis and Destruction in Hinduism. In J. P. Waghorne, N. Cutler \& V. Narayan (Eds.), Gods of Stone: The Embodiment of Divinity in India. New York: Columbia University Press.

\section{Biographical note}

Krishna Balakrishnan is a Toronto based graphic designer and emerging mixed-media artist. His artwork takes a critical view of social, political and cultural issues. Images and text intertwine to narrate a collection of diverse cultural references, oscillating between different systems of representation to evoke non-linear perception of migration, belonging, temporality and displacement. His work can be viewed at bkrishna.com. 